\title{
A Tributação na era da Responsabilidade Fiscal: Desafios e Estratégias
}

\section{Taxation in the era of Fiscal Responsibility: Challenges and Strategies}

\author{
José Maria Dias Filho \\ zemariadias@uol.com.br \\ UFBA
}

\begin{abstract}
Resumo
Partindo do princípio de que a eficácia do sistema tributário não depende apenas de sua configuração legal, mas também de estratégias que viabilizem a captação de receitas com critérios de justiça e respeito à cidadania, o presente trabalho aponta alguns desafios que recaem sobre a Administração Tributária no contexto da Lei de Responsabilidade Fiscal. Em paralelo, apresentam-se alguns mecanismos que podem ser utilizados para que a máquina arrecadadora se torne mais eficiente e menos onerosa para a sociedade. Conclui-se que muitos defeitos atribuídos ao sistema tributário, tais como má distribuição do ônus fiscal entre os contribuintes e interferência excessiva no funcionamento da economia, estão associados à fragilidade dos mecanismos de gestão utilizados pelo próprio sistema. As deficiências mais pronunciadas relacionam-se com a prevenção de riscos de sonegação e com o estímulo ao cumprimento voluntário das obrigações fiscais. Nesse cenário, o Estado torna-se cada vez mais dependente de fontes já sacrificadas, como os assalariados, e de artifícios igualmente cômodos, porém pouco adequados sob o ponto de vista da economia, a exemplo da CPMF.

Palavras-chave: Responsabilidade fiscal, tributação e administração tributária.
\end{abstract}

\section{Abstract}

Assuming that the effectiveness of the tax system depends not only on its legal configuration, but also in strategies that enable the collection of revenue as criteria of justice and respect for citizenship, this paper points out some challenges that fall on the Tax Administration in the context of Fiscal Responsibility Law. In the same way, it presents some mechanisms that may be used so that the State's machine of capitation becomes more efficient and less burdensome to society. It was concluded that many defects attributed to the tax system, such as poor distribution of tax burden between taxpayers and excessive interference in the economy, are associated with the weakness of management mechanisms used by this system itself. The major deficiencies were related to the risk prevention of tax evasion and with the encouragement of voluntary compliance with tax obligations. In this scenario, the state becomes increasingly dependent on sources already sacrificed, as employees, and also comfortable devices, but not adequate from the point of view of the economy, such as CPMF tax.

Keywords: Fiscal responsibility, taxation and tax administration.

Artigo recebido em: 12.12.2011; Aceito em: 22.12.2011

\section{INTRODUÇÃO}

O principal objetivo deste trabalho é apontar alguns desafios que recaem sobre o sistema tributário na Era da Responsabilidade Fiscal e, ao mesmo tempo, apresentar estratégias que podem ser acionadas para que a máquina arrecadadora se torne mais eficiente e menos 
onerosa para a sociedade. Mais particularmente, pretende-se contribuir para disseminar a cultura da eficiência no sistema tributário e explicar por que não basta reformular suas bases legais para que ele se liberte de muitas imperfeições, tais como evasão, alto índice de regressividade, má distribuição da carga tributária e interferência excessiva no funcionamento da economia. A intenção é apontar caminhos para minimizar problemas dessa natureza e, assim, subsidiar a formulação de políticas que viabilizem o aproveitamento racional do potencial tributário disponível em cada ente da federação.

Considerando ainda que o principal objetivo da Administração Tributária é garantir o cumprimento voluntário das obrigações fiscais, tanto para assegurar a regularidade dos fluxos de arrecadação como também para minimizar custos incorridos no processo de captação das receitas, o trabalho procura apontar estratégias que estimulem cada cidadão a repelir práticas contrárias aos interesses do fisco. Adicionalmente, busca-se motivar a sociedade para defender a cultura da responsabilidade fiscal não apenas no que se refere à aplicação dos recursos públicos, mas também no tocante à forma como eles são arrecadados. Afinal, a eficácia da gestão tributária não pode ser aquilatada apenas pelo volume que se arrecada, até porque se o fisco tenta compensar ineficiências sugando mais de estratos sociais que já se encontram penalizados pela má distribuição de renda, o tributo acaba servindo para reforçar injustiças e não para corrigi-las. Portanto, quem mais arrecada não é necessariamente o que melhor arrecada.

\section{JUSTIFICATIVAS}

Com o advento da Lei de Responsabilidade Fiscal e a conseqüente pressão para que o Estado limite seus gastos ao volume de receitas próprias, o funcionamento do sistema tributário voltou ao centro das atenções na esfera governamental e em diversos segmentos da sociedade. De um lado, cresce a consciência de que é necessário manter a arrecadação em níveis elevados para suprir as demandas sociais sem comprometer o equilíbrio das contas públicas, mas também aumenta a percepção de que boa parte da população já chegou ao extremo de sua capacidade contributiva. Como mencionamos anteriormente, estima-se que o contribuinte de classe média está consumindo mais de quatro meses de trabalho para levantar recursos necessários ao cumprimento de obrigações tributárias.

Nos diversos setores da economia, também não se encontra mais espaço para ampliar a arrecadação com aumento de alíquotas, expansão das bases de incidência, criação de novos tributos etc. Estudos indicam que o sistema atual já onera demasiadamente a produção, prejudicando a competitividade de bens e serviços nos mercados interno e externo, bem como a geração de novos postos de trabalho (BATISTA JÚNIOR, 2002). Aliado a isso, tem-se o fato de que todo o aparato vigente sobrecarrega uma massa de contribuintes que dispõem de menos oportunidades para escapar à ação do fisco, contribuído, assim, para agravar ainda mais o problema da distribuição de renda. Temos, portanto, um sistema tributário que pode até ser considerado satisfatório sob o aspecto quantitativo, tanto que conseguiu levantar receitas em montante equivalente a mais de $36 \%$ do PIB no ano passado, porém reconhecidamente injusto sob o ponto de vista social.

Diante disso, o trabalho procura fortalecer a consciência de que o grande desafio que pesa sobre o sistema tributário não é propriamente a manutenção de um fluxo de receitas necessário à cobertura dos gastos públicos, por mais que isso seja necessário para garantir o equilíbrio fiscal e um desenvolvimento sustentável. O maior desafio, isto sim, é levantar tais recursos sem agravar ainda mais as péssimas condições de vida a que se encontra submetida boa parte da população. Isso significa amenizar a carga que incide sobre as atividades produtivas, ajustá-la à capacidade contributiva dos cidadãos, promover uma melhor 
distribuição do ônus tributário, ou seja, tratar o tributo não apenas como um meio de financiamento das despesas públicas, mas como um instrumento de construção da cidadania. Não se trata, pois, de encontrar caminhos para sustentar a arrecadação em níveis elevados a qualquer custo, mas de induzir cada ente da Federação a explorar o potencial tributário disponível de forma justa e racional.

Sempre que se discutem problemas dessa natureza, geralmente as bases legais do sistema tributário são eleitas como o principal elemento a ser ajustado. Raramente, considera-se que boa parte das distorções acima referidas tem origem em certas limitações da Administração Tributária. O trabalho vem contribuir para desfazer alguns mitos do gênero e alertar os formuladores de políticas públicas para a necessidade de considerar outras vias de ajuste, que não apenas reformas legais. Um desses mitos é o de que tais reformas poderão conferir ao sistema atual virtudes que até hoje ele não conseguiu incorporar ou livrá-lo do conjunto de mazelas que a ele se atribuem. Isso é tão improvável quanto esperar que uma lei seja capaz de destruir uma cultura milenar em questão de segundos.

\section{FUNDAMENTAÇÃO TEÓRICA}

\subsection{O Princípio da Neutralidade}

O Princípio da Neutralidade estabelece que o sistema tributário deve atuar de tal forma que não prejudique o funcionamento da economia, isto é, que não comprometa o uso eficiente dos recursos disponíveis. Nas palavras de Rezende (2001, p. 158), "a neutralidade refere-se à nãointerferência sobre as decisões de alocação de recursos baseadas no mecanismo de mercado”. Esse autor explica que se tais decisões se baseiam em preços relativos determinados pelo mercado, o referido princípio seria preservado quando a captação de recursos tributários não modificasse esses preços. Em sua avaliação, qualquer mudança nos preços relativos provocada por alterações na tributação contribui para reduzir o grau de eficiência das decisões econômicas e, por conseguinte, o nível geral de bem-estar dos indivíduos.

Musgrave e Musgrave (1980) também alertam para o fato de que a tributação pode afetar o nível de eficiência na alocação dos recursos disponíveis na economia, gerando efeitos sobre a capacidade de produção, o nível de emprego, a renda, o consumo etc. Por isso, destaca-se que uma determinada política tributária pode ser superior no tocante aos resultados distributivos, mas inferior em relação aos seus efeitos sobre a eficiência, o crescimento e o emprego. Para avaliar tais conseqüências, antes de tudo é preciso considerar que a repercussão do ônus tributário pode ser bem mais ampla do que aquela prevista na legislação. Isso porque a carga tributária pode levar os contribuintes, tanto no caso de pessoa física como jurídica, a ajustar suas decisões de vendas e compras, alterando, assim, o comportamento dos diversos elos que formam as cadeias produtivas.

Ajustes dessa natureza podem ser visualizados nos seguintes exemplos fornecidos por Musgrave e Musgrave (1980): (a) a incidência do imposto de renda sobre determinada atividade pode levar a uma diminuição da jornada de trabalho ou produzir um aumento no custo da mão de obra e, assim, afetar o consumidor; (b) a incidência de determinado tributo sobre a venda de automóveis pode levar os revendedores à majoração de preços e, consequentemente, induzir potenciais compradores a modificar suas decisões de consumo; (c) um imposto sobre o uso do capital pode levar uma empresa a substituir capital por trabalho, e assim por diante; (d) tratamento diferenciado para alguns setores produtivos pode induzir investidores a priorizar certas atividades em detrimento de outras; (e) os critérios de depreciação fixados pela legislação fiscal podem interferir na política de imobilização de 
capital e até mesmo nos métodos de produção; (f) o tratamento tributário concedido a determinados gastos pode interferir na estrutura orçamentária das unidades empresariais.

Esse raciocínio sobre os efeitos econômicos da tributação apoia-se na idéia de que os indivíduos e organizações tendem a transferir para terceiros a carga tributária que lhes é imposta. De acordo com Filellini (1990), esse fato pode afetar o comportamento econômico dos agentes de mercado, especialmente no que se refere ao desenvolvimento de certas funções básicas, como as do trabalho, produção, poupança, risco empresarial e consumo. Num segundo momento, tais alterações poderão atingir a oferta e demanda, preços, alocação de recursos e nível de investimentos, emprego e renda, explica o referido autor. Ainda segundo Filellini (1990), mesmo que não se possa repassar o ônus tributário, sérias repercussões econômicas podem ocorrer. Como exemplo, citam-se alterações nos planos de investimentos da empresa, em suas linhas de produtos, entre outras que poderão resultar de reduções nos lucros do contribuinte.

Para facilitar a compreensão do que significa neutralidade no âmbito do sistema tributário, Giambiagi e Além (2000) fazem referência ao mecanismo da tributação via imposto de renda. Explica-se que esse tributo promove redução da renda disponível dos indivíduos, diminuindo de forma homogênea as suas possibilidades de consumo. Assim, não se provoca viés em relação ao consumo de nenhum bem específico e, por conseguinte, à sua produção, explicam os autores. Continuando, afirma-se que, nesse caso, a tributação é até certo ponto neutra porque não afeta a eficiência nas decisões de alocação de recursos para a produção e o consumo de mercadorias e serviços.

O mesmo não pode ser dito em relação aos chamados tributos seletivos que incidem sobre o consumo, como o ICMS, por exemplo. Nesse caso, um eventual decréscimo no consumo de certos bens e serviços provocado pela tributação poderá estimular a demanda de outros e, consequentemente, mudanças na alocação de recursos produtivos. Naturalmente, isso só se justifica quando se faz necessário interferir no mercado para harmonizar as decisões da iniciativa privada com as necessidades da sociedade como um todo. É o que ocorre, por exemplo, com a tributação que incide sobre o comércio exterior e a riqueza. Em caso contrário, a carga tributária poderá inibir o uso eficiente dos recursos disponíveis e promover distorções na distribuição de renda, gerando redução no nível de bem-estar da própria sociedade (VARSANO, 1999).

Sob a ótica da teoria econômica de caráter marginalista/neoclássico, o ideal é que a captação das receitas tributárias seja tão eficiente que não chegue a exercer nenhum tipo de influência sobre a alocação dos recursos disponíveis na sociedade. Parte-se da idéia de que a carga tributária que recai sobre determinadas atividades econômicas, bem como sobre a renda dos indivíduos, pode pressionar o custo dos bens e serviços e reduzir a liberdade de escolha dos consumidores, comprometendo, desse modo, o bem-estar da sociedade. Em suma, entende-se que os preços relativos da economia não devem ser modificados pelo governo, mas sim pelas forças típicas de mercado. Em condições naturais, quando ocorrem variações, o próprio mercado se encarrega de restabelecer o equilíbrio pela relação entre produtores e consumidores, apregoam os neoclássicos.

\subsection{O Princípio da Equidade}

Outro princípio que a teoria consagra como essencial ao bom funcionamento de um sistema tributário é o da Equidade. Este diz respeito à distribuição do ônus tributário, pois estabelece que cada indivíduo deve contribuir com uma parcela justa para cobrir os gastos públicos. Sob tal preceito, não apenas o ordenamento jurídico, mas também a própria Administração Tributária, devem evitar que os contribuintes sejam onerados de forma desigual. O destaque 
que se dá ao papel da administração, nesse contexto, deve-se ao fato de que a legislação por si só não pode garantir que a tributação se processe de forma eqüitativa. Basta considerar que fenômenos como a sonegação introduzem sérias distorções no sistema, expondo os contribuintes a tratamento desigual.

Rezende (2001) explica que o princípio da equidade pode ser avaliado sob dois enfoques principais: um propõe que o ônus da tributação seja dividido entre os indivíduos de acordo com o benefício que cada um obtém da produção governamental de bens e serviços; o outro sugere que essa divisão se realize em função da capacidade individual de pagar o tributo. A primeira abordagem é conhecida como o Princípio do Benefício, e a segunda como o Princípio da Capacidade de Contribuição, completa o autor. Embora existam considerações teóricas sobre o mérito de cada alternativa, a preferência do sistema tributário brasileiro tem recaído sobre a segunda, isto é, sempre que possível considera-se a capacidade contributiva do indivíduo como critério de imposição da carga tributária.

\subsubsection{O CRITÉRIO DO BENEFÍCIO}

Sob o critério do benefício, considera-se que um sistema tributário respeita o princípio da equidade quando se cobra do contribuinte uma quantia diretamente relacionada com os benefícios que ele recebe do governo (LONGO,1984). Na prática, porém, nem sempre é possível adotar esse critério, pois o valor que os indivíduos atribuem aos benefícios gerados pelo consumo dos bens públicos não é conhecido pelo governo e, portanto, precisaria ser evidenciado mediante processo eleitoral. Ademais, tendo em vista que as preferências podem divergir de indivíduo para indivíduo, não seria conveniente aplicar qualquer fórmula tributária geral à sociedade como um todo (GIAMBIAGI E ALÉM, 2000).

De forma semelhante, Rezende (2001) também considera que existem algumas restrições de ordem prática à adoção generalizada do princípio do benefício na tributação. Em sua avaliação, uma delas diz respeito à dificuldade de obter versões quantitativas de curvas de demanda individual por bens públicos para posterior identificação dos benefícios que cada indivíduo atribui ao consumo de diferentes quantidades de tais bens. E mesmo que isso fosse possível, explica o autor, não se poderia agregar as preferências individuais, já que elas refletem padrões essencialmente subjetivos de avaliação. Adicionalmente, há de se considerar que se o consumo é coletivo certamente os indivíduos não se sentiriam estimulados a declarar corretamente suas preferências, se tal informação fosse utilizada para diferenciar o montante individual de contribuição, acrescenta.

\subsubsection{O CRITÉRIO DA CAPACIDADE CONTRIBUTIVA}

Em decorrência das dificuldades supracitadas, o princípio do benefício se aplica basicamente a situações em que bens e serviços públicos específicos são fornecidos diretamente ao indivíduo, por meio de taxas, contribuições de melhoria, tarifas ou pedágios (LONGO, 1984). Considera-se que a adoção desse critério é viável para financiar bens e serviços cujos benefícios possam ser associados a indivíduos em particular ou quando se assemelham aos bens privados, isto é, quando não se mostram totalmente alinhados com o conceito de nãorivalidade. Ainda segundo Longo, nessa categoria enquadram-se alguns tipos de transporte, de educação e de serviços de utilidade pública. Esse autor acrescenta que quando o bem é rival e os benefícios são internalizados via taxa ou tarifas, o governo atua como se fosse uma entidade do setor privado.

Como se observa, são poucas as situações em que se pode adotar o princípio do benefício como diretriz para a captação das receitas tributárias. Consequentemente, o volume de 
recursos que se obtém sob a égide desse mecanismo se distancia em muito do total dos gastos públicos. E mesmo que ele fosse capaz de proporcionar receitas suficientes para custear as atividades governamentais, nesse caso a tributação só serviria à função alocativa. Isso significa que o governo ficaria impedido de assumir as funções de estabilização e distribuição. Assim, torna-se necessário encontrar uma regra geral de tributação que se adeqüe ao princípio da equidade e, ao mesmo tempo, viabilize o cumprimento de todas as funções supracitadas. $\mathrm{O}$ critério que vem preencher essa lacuna é o chamado Princípio da Capacidade de Contribuição que, como mencionamos, prevê a distribuição do ônus tributário segundo a capacidade de pagamento de cada indivíduo (LONGO, 1984).

Segundo Pires (1996), a ideia de que a tributação deve ser exercida de acordo com a capacidade de pagamento de cada pessoa tem origem nos filósofos contratualistas que, embora adeptos do princípio do benefício, identificaram no primeiro um meio legítimo de levantar recursos para financiar as atividades estatais sem vínculos com contrapartidas específicas. Pires (1996) explica que na noção de contrato social concebida por tais filósofos (Hobbes, Locke, Rousseau) o Estado atua como árbitro e garantidor dos direitos e deveres das partes e, portanto, a sua existência torna-se de interesse coletivo e de cada um em particular. Logo, seria admissível que todos contribuíssem para a sua manutenção, respeitando-se a capacidade econômica. A propósito, alguns clássicos do pensamento econômico também expuseram a idéia de que todos os cidadãos devem contribuir para o custeio das atividades públicas de acordo com suas possibilidades. Smith (1983, p. 247-8), por exemplo, faz referência a tal princípio valendo-se das seguintes considerações:

\footnotetext{
Os súditos de cada Estado devem contribuir o máximo possível para a manutenção do governo, em proporção a suas respectivas capacidades, isto é, em proporção ao rendimento que cada indivíduo desfruta, sob a proteção do Estado. As despesas de governo, em relação aos indivíduos de uma grande nação, são como as despesas de administração em relação aos rendeiros associados de uma grande propriedade, os quais são obrigados a contribuir em proporção aos respectivos interesses que têm na propriedade. É na observância ou não observância desse princípio que consiste o que se denomina de equidade ou falta de equidade da tributação.
}

Segundo esse princípio, indivíduos que se encontrem sob as mesmas condições em termos de renda e bem-estar devem assumir o ônus tributário na mesma proporção, isto é, devem ser expostos ao mesmo nível de sacrifício. Tem-se aí a chamada equidade horizontal. De forma geral, pode-se afirmar que esse critério consiste em submeter ao mesmo tratamento pessoas que se encontrem em posições idênticas sob o ponto de vista econômico. Porém, quando o tratamento tributário se diferencia em função da capacidade de pagamento de cada um, tem-se aí a denominada equidade vertical. Sob esse último critério, a grande questão é definir o perfil da tributação que deve incidir sobre indivíduos com rendas desiguais.

Partindo do pressuposto de que a utilidade marginal da renda é decrescente, considera-se que um sistema tributário aderente ao princípio da equidade deve extrair proporcionalmente mais dos que possuem maior nível de renda. Segundo Rezende (2001), essa ideia implica não apenas aceitar que a utilidade marginal da renda é decrescente, mas também que a respectiva taxa de decréscimo se comporta de acordo com os requisitos referentes a diferentes critérios de igualdade de sacrifício. Esse autor afirma ser difícil comparar tais suposições, visto que o conceito de utilidade refere-se a uma avaliação individual e subjetiva. Assim, é possível que um mesmo nível de renda proporcione diferentes graus de utilidade para diferentes categorias de indivíduos, de tal forma que um 'igual sacrifício' seria obtido com diferentes níveis de contribuição, completa Rezende.

Como se vê, a literatura parece confirmar que o sistema progressivo se reveste de uma lógica bastante defensável. Assim, é legítimo que a própria sociedade tenha grande interesse na 
identificação dos fatores que contribuem para que a tributação caminhe em sentido oposto, como ocorre atualmente.

\section{DESAFIOS QUE RECAEM SOBRE A TRIBUTAÇÃO NA ERA DA RESPONSABILIDADE FISCAL}

Concebida para prevenir riscos e corrigir desvios que possam afetar o equilíbrio das contas públicas, a Lei Complementar $\mathrm{n}^{\circ}$. 101/2000, conhecida como Lei de Responsabilidade Fiscal (LRF), tem sido considerada um dos marcos mais significativo na história políticoadministrativa do País. Com ela, busca-se um ajuste fiscal de caráter permanente que possibilite o fortalecimento da situação financeira dos entes da Federação e viabilize investimentos em programas de desenvolvimento social e econômico. Parte-se do princípio de que o Estado deve ser esforçar cada vez mais para financiar seus gastos com recursos próprios, já que a autonomia financeira de cada ente da Federação é vista como condição fundamental ao equacionamento do problema da dívida pública e à recuperação do desenvolvimento econômico sustentável.

Como se pode deduzir, a referida lei expõe o sistema tributário a um conjunto de desafios, já que a consecução de seu principal objetivo, o equilíbrio das contas públicas, fica a depender em muito do desempenho da arrecadação. Em primeiro lugar, é preciso considerar que não basta maximizar a captação de recursos tributários. É preciso que se arrecade de forma eficiente, nos limites da lei, respeitando a capacidade contributiva de cada indivíduo e sem comprometer a competitividade dos produtos brasileiros nos mercados interno e externo. Mais do que um mero instrumento de financiamento das atividades estatais, o tributo tem uma dimensão de cidadania que deve ser preservada. Deve atuar como meio de promoção do bemestar social, contribuindo para minimizar os efeitos da pobreza e reduzir as desigualdades sociais.

\section{O Problema da Evasão}

Como a conjuntura atual não recomenda que se amplie o volume arrecadado com a criação de novos tributos ou com aumento de alíquotas para fazer face às crescentes demandas sociais, nota-se que um dos principais desafios do sistema tributário é bloquear os mecanismos de evasão. Não se sabe ao certo a que nível chega a perda de receitas em todo o País, mas há quem considere que a relação entre o volume arrecadado e o sonegado equivale a 1 (um), ou seja, para cada real capturado pelo sistema, um acabaria escapando pelo ralo da sonegação. Os mais otimistas avaliam que esse índice está na casa dos 70\%. De qualquer forma, estudos sugerem que a relação entre a base efetivamente tributada e a permitida pela estrutura econômica é muito baixa. Estima-se que esse número já esteve na faixa dos $37 \%$ a $41 \%$ para o Imposto de Renda, entre $36 \%$ e $45 \%$ no caso do IPI e ICMS e, finalmente, em $14 \%$ no caso do ITR - Imposto Territorial Rural (DIAS FILHO, 2003).

Em geral, considera-se que esse quadro tende a piorar com o fortalecimento da globalização de mercados e com o advento de novas tecnologias da informação. Essa previsão parte do seguinte princípio: se a Administração Tributária já sofre grandes limitações para prevenir riscos de evasão num ambiente em que ainda se pode localizar fisicamente a maior parte das atividades econômicas, mais elevada será a sua dificuldade num cenário em que os fluxos financeiros e comerciais ganham enorme mobilidade. A expansão do volume de operações que se desenvolvem eletronicamente diminui o significado dos limites geográficos e, ao mesmo tempo, dificulta a identificação daquelas que estão no campo da incidência. Adicionalmente, considera-se que esse fato amplia o espaço para a competição tributária 
internacional, podendo estimular novas formas de planejamento fiscal e até mesmo aumentar as chances de evasão (AFONSO, 2000).

Assim, realmente torna-se cada vez mais difícil obter números que expressem o volume de recursos que se deixa de arrecadar por conta da sonegação. Contudo, qualquer que seja a magnitude desse fenômeno, a tributação será sempre percebida como injusta pelos que não dispõem de oportunidades para evitá-la e pelos que cumprem suas obrigações por questões de princípio e cidadania. Esse sentimento de injustiça, que se aguça ainda mais com o problema da impunidade, pode comprometer a continuidade do sistema em longo prazo. Esta é uma das razões pelas quais os mecanismos de gestão tributária estão se transformando numa preocupação cada vez mais presente na agenda de países que se encontram em via de desenvolvimento. No que se refere ao problema da evasão, em particular, estudos realizados pela equipe de assuntos fiscais do Fundo Monetário Internacional Silvani e Baer (1997) revelam que uma de suas principais causas é exatamente a fragilidade dos instrumentos de fiscalização. Esse mesmo trabalho reconhece a influência de outros fatores, tais como a percepção de que o sistema tributário é injusto, o elevado grau de complexidade da legislação fiscal e a insuficiência de programas de educação tributária. Porém, não resta dúvida de que a debilidade dos mecanismos de fiscalização realmente é o que parece assumir maior significado no conjunto. Isso porque, como bem nos lembra Batista Jr. (2002), se os contribuintes percebem que a administração tributária não dispõe de meios adequados para fiscalizar e garantir o cumprimento da legislação, a evasão tende a se alastrar de forma inevitável.

Como se observa, esta é mais uma razão pela qual não se pode esperar que as distorções do sistema tributário possam ser inteiramente corrigidas com ajustes de ordem legal. Quando não se consegue induzir os principais estratos de contribuintes ao cumprimento de suas obrigações, a tributação tende a continuar sendo regressiva e, por conseguinte, socialmente injusta, ainda que se encontre legalmente ancorada no princípio da progressividade. Afinal, em tais circunstâncias, dificilmente o Estado poderá amenizar a carga tributária que recai sobre segmentos já sacrificados, como é o caso do conjunto de trabalhadores que recebem seus proventos diminuídos pelos mecanismos de retenção na fonte.

\section{O Aprimoramento dos Mecanismos de Gestão}

Outro desafio que emerge com mais vigor na era da responsabilidade fiscal é fortalecer os mecanismos da Administração Tributária, notadamente nas esferas estadual e municipal. Segundo Batista Jr. (2002), com uma administração desprovida de recursos humanos e materiais em escala e qualidade compatíveis com uma economia complexa e de magnitude continental como a brasileira, o sistema tributário, por melhor concebido que seja sob o ponto de vista legal, deixará fatalmente a desejar em termos de qualidade, eficácia e justiça social. Em sua avaliação, o apego do governo a tributos de maior produtividade fiscal, mas inadequados sob o ponto de vista econômico, como a CPMF, deve-se, em larga medida, à fragilidade da administração tributária e do sistema de fiscalização. Essa relação entre a qualidade do sistema tributário e seus mecanismos de gestão também foi reconhecida por Kaldor (1962), um dos clássicos da macroeconomia do pós-guerra:

Nunca é demais insistir que a eficácia do sistema tributário não é apenas uma questão de legislação tributária apropriada, mas de eficiência e integridade da administração tributária. Em muitos países subdesenvolvidos, o baixo rendimento da tributação só pode ser atribuído ao fato de a lei tributária não ser imposta com a necessária firmeza, seja em virtude da incapacidade da administração, seja simplesmente por causa da existência de corrupção na administração. Nenhum 
sistema legal, por mais cuidadosamente concebido, está imune ao conluio entre os administradores tributários e os contribuintes; uma administração eficiente, formada por pessoas de grande integridade, é o principal requisito para que se possa explorar o potencial tributário de um país.

Esse é um problema que precisa ser observado com atenção, até porque se cada estado ou município não exercitar suas atribuições e explorar o potencial de receita própria em plenitude, poderá sofrer sanções que em muito dificultam a sua administração. Uma das principais está prevista na própria LRF, haja vista que ela veda a realização de transferências voluntárias para o ente que não instituir, prever e arrecadar todos os impostos de sua competência. Contrair empréstimos para cobrir despesas correntes é um remédio que legalmente também deixa de existir na referida circunstância.

As deficiências que limitam a eficácia da máquina arrecadadora municipal e o reconhecimento de que existe um enorme potencial tributário a ser explorado chegaram a motivar a inclusão de um dispositivo na LRF segundo o qual a União deve prestar assistência técnica e cooperação financeira aos municípios para modernizar suas administrações tributárias. Essa assistência inclui treinamento e desenvolvimento de recursos humanos, bem como transferência de tecnologia. O Programa para Modernização das Administrações Tributárias Municipais (PMAT), lançado pelo Banco Nacional de Desenvolvimento Social (BNDES) é um exemplo do esforço que tem sido realizado para incentivar a captação de receita própria na esfera municipal.

Como se observa, nos três níveis de governo, a gestão tributária está sendo desafiada a se instrumentalizar para atuar com mais eficiência e, assim, buscar aproximar cada vez mais a receita arrecadada da receita potencial. Isso porque, sabe-se, a estabilidade fiscal não se conquista automaticamente com a simples edição de uma lei, por mais consistentes que sejam os seus fundamentos. Pelo contrário, o equilíbrio das contas públicas é sempre uma meta que depende, de um lado, do grau de eficiência da máquina arrecadadora e, de outro, do compromisso de limitar gastos ao volume de recursos disponíveis. Assim, deixar de arrecadar cada centavo a que o Estado tem direito, ou fazê-lo de forma pouco eficiente, é tão pernicioso aos interesses da sociedade quanto aplicar mal o dinheiro público.

Daí a necessidade de identificar técnicas de gestão que estimulem o exercício da atividade tributária segundo os princípios da LRF. Comportamentos irracionais como facilitar práticas de sonegação e, mais tarde, tentar recuperar a receita com ações onerosas e desprovidas de base técnica tornam-se intoleráveis na Era da Responsabilidade Fiscal. De uma vez por todas, a Lei veio retirar dos gestores a oportunidade de fazer de suas repartições fiscais laboratórios para experimentos nem sempre exitosos. Hoje, todos ficam obrigados a observar princípios de planejamento e controle, tais como estimar riscos, estudar o comportamento da curva da receita, avaliar o impacto de políticas fiscais sobre a arrecadação, identificar fatores que possam comprometer o fluxo de receitas e buscar a melhor relação custo-benefício em suas ações.

$\mathrm{O}$ gerenciamento de riscos fiscais, em particular, tornou-se mandamento de primeira ordem no conjunto das disposições emanadas da LRF. Para assegurar o cumprimento de metas de resultados entre receitas e despesas, determina-se que nenhum ente da Federação poderá conceder benefícios fiscais, como anistia, isenções, incentivos e subsídios, sem a devida análise de seus efeitos sobre a curva da receita. De igual forma, todos ficaram obrigados a fixar metas de arrecadação, estimando adequadamente as receitas que poderão auferir, mediante consideração de diversos fatores determinantes de crescimento ou diminuição, tais como sinais de inadimplência, variação do índice de preços, retração da economia etc. Nas previsões de arrecadação, deverão especificar, inclusive, medidas de combate à sonegação e evasão, bem como estabelecer procedimentos que lhes permitam acompanhar a evolução dos 
créditos tributários passíveis de cobrança administrativa. Somando-se a outras obrigações, tais como preparar demonstrativos de evolução da receita referente aos três últimos exercícios, realizar projeções para os dois seguintes e evidenciar metodologias de cálculos e premissas utilizadas, tem-se um leque de atividades que nos dão uma idéia do grau de aperfeiçoamento a que deve ser submetida a Administração Tributária de muitos estados e municípios.

\section{A Redução de Custos Operacionais}

A redução dos custos operacionais do sistema tributário é mais um desafio que se impõe à máquina arrecadadora no contexto da Lei de Responsabilidade Fiscal. A literatura sugere que os impactos negativos da tributação sobre o funcionamento da economia podem estar relacionados também com os custos operacionais do sistema tributário, que são os recursos consumidos desde a sua concepção legal até o desenvolvimento das atividades de arrecadação e fiscalização propriamente ditas. Aliás, considera-se que nessa categoria também se incluem os recursos consumidos pelo Poder Judiciário no processo de análise e julgamento de conflitos entre fisco e contribuinte. De fato, a experiência comprova que em muitas situações, por questões de interpretação da legislação e outros fatores de ordem operacional, surgem divergências que deságuam no Judiciário, acarretando custos para as partes envolvidas.

Embora inevitáveis sob certos aspectos, os chamados custos administrativos também podem prejudicar o bem-estar da sociedade, uma vez que implicam diminuição de recursos destinados à formação da cesta de bens e serviços públicos e, além disso, contribuem para pressionar a carga tributária. Segundo Musgrave e Musgrave (1980), tais custos serão tão mais significativos quanto maior for a complexidade dos tributos a serem administrados e mais energicamente eles forem postos em vigor. Em outras palavras, o seu comportamento está associado à qualidade dos mecanismos que a Administração Tributária aciona para atingir suas metas. Este é um aspecto que interessa de perto ao presente estudo.

Do ponto de vista da Controladoria, afirmar que a Administração Tributária deve minimizar tais custos talvez não seja adequado. Mas dizer que esforços devem ser canalizados para se atingir a melhor relação possível entre volume arrecadado e custos operacionais, certamente sim. Isso implica identificar e selecionar alternativas de ação que proporcionem os melhores resultados. Em se tratando de Administração Tributária, o melhor resultado significa captar todos os recursos que lhe permitem a legislação e a base econômica, de forma voluntária. Esse é o motivo pelo qual se recomenda simplificar o sistema tributário, aprimorar os mecanismos de controle, levar o contribuinte a perceber certos riscos e promover uma conscientização acerca do significado social do tributo.

Silvani e Baer (1997), em estudos realizados sob coordenação do Fundo Monetário Internacional-FMI, salientam que um dos mecanismos mais eficazes para reduzir custos associados ao processo de captação das receitas tributárias é induzir o contribuinte ao cumprimento voluntário de suas obrigações. Nesse estudo, destaca-se que um princípio amplamente aceito no âmbito da Administração Tributária é o de que o seu principal objetivo é levar o contribuinte a cumprir a legislação espontaneamente. Os autores enfatizam que punir e mobilizar recursos para recuperar receitas sonegadas não chega a ser a finalidade última da fiscalização, embora se considere que a percepção da existência de mecanismos de controle pode ajudar a inibir práticas contrárias aos interesses do fisco.

Dolan (1999) compartilha desse entendimento, afirmando que qualquer Administração Tributária moderna tem como objetivo principal alcançar o maior grau possível de cumprimento voluntário das obrigações fiscais. Em sua avaliação, o alto grau de voluntariedade nessa área gera benefícios econômicos, sociais e políticos de grande significado para toda a sociedade. Como exemplo, destacam-se: (a) o Estado pode dispor de 
todos os recursos a que tem direito em tempo hábil para cumprir seus objetivos e, assim, minimizar custos com empréstimos; (b) um fluxo de receitas consistente e previsível contribui para fortalecer a estabilidade econômica; (c) desenvolve-se entre os cidadãos um sentimento de justiça ao perceberem que, indistintamente, todos são chamados a contribuir; e (d) eleva-se o grau de confiança na ação governamental, na medida em que cidadãos percebem que a Administração Tributária é justa e eficiente.

Tanzi e Pellechio (1995), em estudos realizados para identificar causas de ineficiências nos sistemas tributários de países em desenvolvimento, concluem que esforços adicionais devem ser empreendidos para melhorar o grau de voluntariedade no cumprimento das obrigações fiscais. Além de eliminar certas complexidades operacionais, melhorar a qualidade da legislação tributária e aparelhar a máquina arrecadadora, recomenda-se investir em estratégias que estimulem o contribuinte a honrar seus compromissos voluntariamente. Considera-se que esse é o caminho mais adequado para viabilizar o aproveitamento do potencial tributário disponível em cada país ao menor custo possível.

\section{A Legitimação Social das Instituições Tributárias}

Outro desafio que merece ser considerado nesse contexto é a legitimação social das instituições tributárias. Como mencionamos anteriormente, em geral considera-se que o principal objetivo da Administração Tributária é induzir o contribuinte ao cumprimento voluntário de suas obrigações. Essa idéia baseia-se no fato de que tal comportamento facilita a captação das receitas disponíveis ao menor custo possível, inclusive do ponto de vista político. Além de evitar esforços para recuperar receitas sonegadas, recolhimentos espontâneos podem garantir maior regularidade ao fluxo de arrecadação. Porém, esta é uma meta que traz certos desafios. Um dos principais é identificar mecanismos que minimizem áreas de atrito entre fisco e contribuinte e, adicionalmente, levem a sociedade a visualizar o tributo como um instrumento de construção da cidadania, ou seja, como algo que lhe é benéfico.

A história demonstra que pagar impostos nunca foi uma atividade pela qual o cidadão pudesse se sentir atraído, mormente em sociedades onde se tem motivos para duvidar do retorno dos recursos transferidos ao ente público. Assim, se a carga tributária for percebida como injusta e, além disso, o próprio fisco criar embaraços para o contribuinte, é de se esperar pouca vontade de contribuir espontaneamente. Uma condição fundamental para que o cidadão desenvolva comportamentos favoráveis aos objetivos da Administração Tributária, engajando-se, por exemplo, em programas de combate à sonegação, é perceber que existe correspondência entre as ações do poder público e seus próprios interesses. Pelo menos é o que se pode deduzir de teorias segundo as quais o homem age de forma oportunista, buscando maximizar o seu bem-estar. Isso significa que não é suficiente demonstrar a inexistência de desvios do erário, mas que todos os recursos foram aplicados de acordo com as prioridades estabelecidas pela própria sociedade. Esse é um aspecto que precisa ser considerado quando se pensa em otimizar a curva da receita tributária e atrair cada indivíduo para atuar como vetor da chamada justiça fiscal.

Reconhecendo essa necessidade e buscando fortalecer a consciência sobre a função social do tributo, a LRF abre espaço para a participação popular na elaboração de planos governamentais. Além disso, estabelece em seu artigo 49 que as contas apresentadas pelo Executivo deverão ser disponibilizadas, durante todo o exercício, no respectivo Poder Legislativo ou no órgão técnico responsável pela sua elaboração, para consulta pelos cidadãos e instituições da sociedade. Trata-se, pois, de uma exigência tendente a aumentar o nível de transparência da gestão fiscal, particularmente no que se refere à aplicação dos recursos 
arrecadados. Esse é um passo importante para a legitimação social do papel da Administração Tributária, uma vez que se concede ao cidadão a oportunidade de acompanhar a aplicação dos recursos que ele mesmo transferiu para o erário.

Entretanto, é necessário considerar que uma Lei por si própria não é suficiente para alterar comportamentos e motivar cada cidadão a se envolver mais com questões tributárias, especialmente num país onde não se costuma pensar muito em termos de gerações futuras. Mais do que isso é preciso que os dispositivos legais se materializem em instrumentos sintonizados com o mundo existencial de cada cidadão, a começar pela linguagem de seu cotidiano. Sem meias palavras, os relatórios devem ser claros o suficiente para que se perceba quem aplicou adequadamente os recursos públicos e quem desrespeitou o sacrifício do contribuinte. A verdadeira transparência fiscal exige que os instrumentos utilizados no processo da accountability sejam, no mínimo, compreensíveis aos seus destinatários, conforme as seguintes considerações de Cisne (2002, p. 95):

Por transparência, pode-se entender não a mera divulgação de informações, mas também a clareza com que deverá ser feita, por meio de uma linguagem simples, acessível e objetiva, de modo que todo cidadão possa entender a mensagem e opinar sobre as questões apresentadas.

Porém, além de dar transparência aos atos da gestão pública, é necessário mais investimento em justiça social, adequação da carga tributária à capacidade econômica do contribuinte, melhorias no relacionamento entre fisco e contribuinte, entre outros fatores que estimulem comportamentos favoráveis aos objetivos do fisco. Se o tributo não for percebido como instrumento de promoção do bem-estar social, é de se esperar que a eficácia do sistema tributário fique a depender muito mais de mecanismos coercitivos do que da vontade contributiva do indivíduo. Isso significa que não é suficiente demonstrar a inexistência de desvios do erário, mas que todos os recursos foram aplicados de acordo com as prioridades estabelecidas pela própria sociedade. Esse é um aspecto que precisa ser considerado quando se pensa em otimizar a arrecadação tributária e atrair cada indivíduo para atuar como vetor da chamada justiça fiscal.

\section{CONCLUSÕES}

Entre os diversos problemas que comprometem a eficácia do sistema tributário brasileiro, destacam-se a má distribuição do ônus fiscal entre os contribuintes, a interferência dos tributos no funcionamento da economia e a incapacidade de atuar como instrumento de inclusão social. A esperança de que tais problemas possam ser solucionados ressurge a cada instante em que a Reforma Tributária volta à cena e se desfaz nos primeiros momentos em que se aplicam os seus dispositivos. A frustração vem como conseqüência e reforça a impressão de que estamos predestinados a conviver com um sistema tributário ineficiente e socialmente injusto. Afinal, para sustentar a arrecadação em patamares compatíveis com os gastos públicos, novas exigências acabam recaindo sobre os segmentos já sacrificados.

Uma análise mais acurada dos problemas acima mencionados nos leva à conclusão de que realmente nem todos são passíveis de correção mediante reformas constitucionais. Se o sistema não estiver amparado em mecanismos de gestão que lhe permitam explorar o potencial tributário de forma eficiente, não importa quão justa e adequada possa ser a sua base legal. Considerem-se, por exemplo, os efeitos da sonegação. Quando os mais fortes conseguem escapar à tributação, o fisco pode se transformar num vetor de ineficiência econômica e de injustiça social. De um lado, porque a evasão distorce preços relativos, desequilibrando as forças de concorrência que participam do mercado; de outro, porque o 
próprio Estado acaba impondo maiores sacrifícios a fontes mais acessíveis para cumprir suas metas de arrecadação. Os assalariados sujeitos a retenção na fonte ou qualquer cidadão que tenha o "privilégio" de movimentar alguns reais em conta bancária conhecem de perto essa realidade.

Não se discute que, na era da responsabilidade fiscal, é importante que o Estado mantenha a arrecadação em níveis que lhe permitam atender às demandas sociais sem pressionar o déficit do setor público. Afinal, o desequilíbrio orçamentário está na raiz de muitos males que afetam o bem-estar social, entre os quais inflação, taxas de juros elevadas, desemprego e insuficiência de serviços públicos essenciais como saúde, segurança e educação. Porém, é preciso considerar que o tributo não é um simples mecanismo de financiamento das atividades estatais, mas uma forma de promover a justiça social. Isso significa que a Administração Tributária deve aprimorar seus mecanismos de ação para aproveitar o potencial tributário disponível de forma racional. Em vez de optar por procedimentos mais cômodos e incompatíveis com os interesses sociais, como a pesada tributação que incide sobre a folha de pagamento, é necessário melhorar a eficiência da máquina arrecadadora, investindo em tecnologia, combatendo focos de sonegação, melhorando a qualificação de funcionários e, sobretudo, estimulando o cumprimento voluntário das obrigações fiscais.

É nesse cenário, marcado pela premente necessidade de saneamento do setor público, que se insere o presente trabalho. Esperamos, assim, contribuir para que o sistema tributário não apenas se torne mais habilitado a abastecer os cofres do Governo, mas que o faça respeitando a capacidade contributiva dos cidadãos e interferindo o mínimo possível no funcionamento da economia. Nesse sentido, é fundamental reduzir a tributação incidente sobre os setores produtivos, amenizar a carga tributária que recai sobre a folha de pagamento, suprimir tributos de caráter regressivo, desonerar a cesta básica de alimentos e, na medida do possível, eliminar a burocracia. Afinal, não se pode esquecer de que muitos recursos também são desviados do setor produtivo para alimentar procedimentos burocráticos no desenvolvimento de diversas atividades, tais como identificar o valor a ser pago, interpretar a legislação tributária, prestar informações ao fisco, guardar documentos fiscais e treinar pessoal.

Assim, chega-se à conclusão de que o grande desafio que recai sobre o sistema tributário na era da responsabilidade fiscal não é simplesmente assegurar o fluxo de receitas necessário à cobertura dos gastos públicos. Na verdade, o seu maior desafio é levantar tais recursos sem comprometer o desenvolvimento socioeconômico do País e agravar as péssimas condições de vida a que se encontra exposta boa parte da população. É certo que no contexto da responsabilidade fiscal, arrecadar mais e comprimir gastos parece ter assumido o status de primeiro mandamento na gestão pública. Porém, entendemos que isso não justifica a adoção de políticas que possam até contribuir para resolver um problema de caixa, mas ao mesmo tempo ampliar a dívida social. O que se propõe neste trabalho é melhorar o desempenho geral do sistema a partir de mecanismos de gestão, com destaque para estratégias que possam prevenir a evasão de receitas, como, por exemplo, investir na legitimação social das instituições tributárias.

\section{REFERÊNCIAS}

AFONSO, J. R. R.; ARAUJO, E. A. Capacidade de gasto dos municípios brasileiros: arrecadação própria e receita. 2000. Disponível em: < http://www.federativo.bndes.gov.br>. Acesso em: 10 jun. 2003. 
BATISTA JR., P. N. A economia como ela é. 3. ed. São Paulo: Boitempo Editorial, 2002.

CISNE, J. J. N. Administração tributária e democracia participativa - proposta de cidadania fiscal. Editora UVA: Sobral, 2002.

DIAS FILHO, J. M. Gestão tributária na era da responsabilidade fiscal: propostas para otimizar a curva da receita utilizando conceitos de semiótica e regressão logística. Tese apresentada à FEA/USP, São Paulo, 2003.

DOLAN, M. P. Encouraging voluntary compliance: the role of an effective audit program. Seminário Internacional de Fiscalização Tributária. Anais. Vitória (ES), 1999.

FILELLINI, A. Economia do setor público. São Paulo: Atlas, 1990.

GIAMBIAGI, F.; ALÉM, A. C. Finanças públicas. 2. ed. Rio de Janeiro: Campus, 2000.

KALDOR, N. The role of taxation in economic development. Essays on Economic Policy I, Duckworth, London, 1962.

LONGO, C. A. Finanças públicas: uma introdução. São Paulo: IPE-USP, 1984.

MUSGRAVE, R. A.; MUSGRAVE, P. B. Finanças públicas: teoria e prática. Rio de Janeiro: Campus, 1980.

PIRES, V. Estado, mercado e tributação. Piracicaba: Editora UNIMEP, 1996.

REZENDE, F. Finanças públicas. 2. ed. São Paulo: Atlas, 2001.

SILVANI, C.;BAER, K...Designing a Tax Administration Reform Strategy: Experiences and Guidelines, mimeo., International Monetary Fund, IMF Working Paper, WP/97/30, March 1997.

SMITH, A. A riqueza das nações. São Paulo: Abril Cultural, 1983.

TANZI, V.; PELLECHIO, A. The reform of tax administration reform. IMF, Washington, 1995.

VARSANO, R. A fiscalização tributária sob um enfoque econômico. Seminário Internacional de Fiscalização Tributária. Anais. Vitória (ES), 1999. 